\title{
Structural Characterization of Fission Products in Irradiated TRISO Fuels using Transmission Kikuchi Diffraction, Transmission Electron Microscopy, and Synchrotron X-ray Absorption Spectroscopy
}

\author{
Rachel L. Seibert ${ }^{1}$, Jeff Terry ${ }^{1}$, Chad M. Parish ${ }^{2}$, John D. Hunn ${ }^{2}$, Charles A. Baldwin² and Kurt A. \\ Terrani $^{2}$ \\ 1. Illinois Institute of Technology, Department of Physics, Chicago, IL, USA. \\ 2. Oak Ridge National Laboratory, Oak Ridge, TN, USA.
}

The design philosophy of tristructural isotropic (TRISO) coated nuclear fuel particles is to retain radionuclides over a wide range of operational parameters (e.g., power, burnup, and temperature) to ensure safe operation of high-temperature gas-cooled nuclear reactors. Previous studies have indicated the release of metallic fission products $(\mathrm{Ag}, \mathrm{Pd})$ at temperatures that simulate accident scenarios $[1,2]$. The exact mechanism for this release that may involve fission product/SiC interactions remains elusive and requires further study. In this work, we used a multi-faceted approach to analyze the effect of postirradiation heating on $\mathrm{SiC}$ integrity and fission product transport in neutron-irradiated TRISO fuel from the Advanced Gas Reactor Fuel Development and Qualification first irradiation experiment (AGR-1) programs [3]. We combined synchrotron x-ray absorption spectroscopy (XAS), transmission Kikuchi diffraction (tKD), and scanning/transmission electron microscopy (S/TEM) with energy dispersive $\mathrm{x}$-ray spectroscopy (EDS) to gather a comprehensive dataset on the material.

The TRISO particles utilized in this work were fabricated at Oak Ridge National Laboratory [4] and irradiated in the Advanced Test Reactor at Idaho National Laboratory to temperatures reaching $1250^{\circ} \mathrm{C}$ and a burnup of $19.6 \%$ fissions per initial metal atom [5]. After irradiation selected compacts were heated to high temperatures for margin temperature testing to simulate in-reactor accident scenarios [6]. The $\mathrm{SiC}$ shells from three selected particles (one as-irradiated particle, one heated at $1700^{\circ} \mathrm{C}$ for 300 hours, and one heated at $1800^{\circ} \mathrm{C}$ for 600 hours) were isolated by deconsolidating the fuel compact [7]. This was followed by the breaking of the particles, burning off the carbon layers in air at $750^{\circ} \mathrm{C}$, and cleaning any exposed uranium or fission products from the SiC surface with hot nitric acid. XAS was collected on the isolated SiC shells at the Materials Research and Collaborative Access Team (MRCAT) insertion device beam line at the Advanced Photon Source [8]. The Low Activation Materials Development and Analysis (LAMDA) laboratory at ORNL includes a microscopy suite that allows for the examination of low-dose radioactive material, including neutron irradiated fuels [9]. Here, small lamella (liftouts) from the $\mathrm{SiC}$ and the IPyC/SiC and OPyC/SiC interfaces of each of the three shells were prepared and studied using S/TEM, EDS, and tKD to study the microstructure, dispersion, and phase and grain structure of the $\mathrm{SiC}$ and release products. Specimens were analyzed using an FEI Versa3D FIB-SEM DualBeam with Oxford Nordlys EBSD system for tKD, and an FEI Talos F200X system with "SuperX" 4-detector SDD-EDS system for S/TEM and EDS.

Preliminary findings confirm measurable fissile and fission product inventories within the $\mathrm{SiC}$ layers [6, 10]. XAS provided information on the average coordination chemistry of the material. It suggests the formation of uranium carbides, palladium silicides, and metallic silver. From S/TEM, we observed concentrated deposits of actinides and fission products along grain boundaries and at triple points within the $\mathrm{SiC}$, an example shown in Figure 1, suggesting grain boundary diffusion as a dominant diffusion mechanism. Metal fission products were found co-located in the material. Uranium was found in 
isolated pockets, co-located with plutonium, and was sometimes co-located with metallic fission products. Silver was only observed in the $\mathrm{SiC}$ particle annealed to $1700^{\circ} \mathrm{C}$ in small quantities. Although the grain size in the $\mathrm{SiC}$ increased from IPyC to OPyC interface, it remained fairly consistent between particles. With increasing post-irradiation temperature, uranium and palladium migrated further across the SiC layer of the TRISO, but the size of the precipitates decreased as a function of increasing distance from the IPyC. We use tKD to identify larger precipitates in the material to help draw conclusions about the precipitate formation and to confirm composition determined using XAS. Results from these three techniques will be discussed in greater detail in this presentation including their application to future versions of TRISO nuclear fuel [11].

References:

[1] T. D. Gulden and H. Nickel, Nucl. Technol. 39(5) (1977) p. 206.

[2] IAEA-TECDOC-1645, International Atomic Energy Agency (2010).

[3] D. A. Petti et al., JOM 62(9) (2010) p. 62.

[4] R. A. Lowden, ORNL/CF-2006/02, Oak Ridge National Laboratory, Oak Ridge, Tennessee, (2006).

[5] B. P. Collin, INL/EXT-10-18097, Rev. 1, Idaho National Laboratory, Idaho Falls, Idaho (2012).

[6] P. A. Demkowicz et al., INL/EXT-15-36407, Idaho National Laboratory, Idaho Falls, Idaho (2015).

[7] C. A. Baldwin et. al., Nucl. Eng. Des. 271 (2014) p. 131.

[8] C. U. Segre, et. al., CP521, Synchrotron Radiation Instrumentation: Eleventh U.S. National

Conference, ed. P. Pianetta, et al., (American Insitute of Physics, New York, 2000) p. 419-422.

[9] C. M. Parish et. al., Microsc. Microanal. 21(S3) (2015) p. 1003.

[10] I. J. van Rooyen, Y.Q. Wu, and T. M. Lillo, J. Nucl. Mater. 446 (2014) p. 178.

[11] Research was sponsored by the U.S. DOE's Office of Nuclear Energy Advanced Fuel's Campaign of the Fuel Cycle R\&D Program, and the Nuclear Science User Facilities by UT-Battelle, LLC under Contract No. DE-AC05-00OR22725 with the U.S. DOE. FEI Talos F200X S/TEM provided by the DOE, Office of Nuclear Energy, Fuel Cycle R\&D Program and the Nuclear Science User Facilities. MRCAT operations are supported by the DOE and the MRCAT member institutions. This research used resources of the Advanced Photon Source, a U.S. DOE Office of Science User Facility operated for the DOE Office of Science by Argonne National Laboratory under Contract No. DE-AC02-06CH11357.

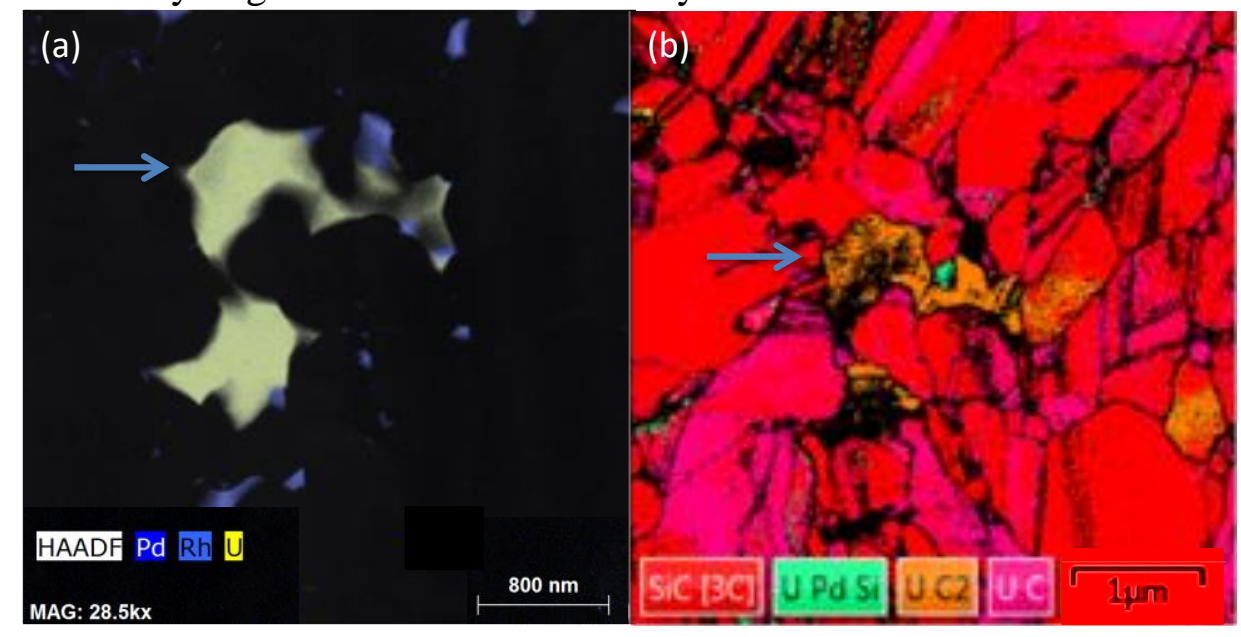

Figure 1. (a) STEM/EDS map of fission product precipitates at the boundaries of SiC grains. In this example, from the as-irradiated particle, uranium is shown both co-located with metallic fission products $\mathrm{Pd}$ and $\mathrm{Rh}$, and on its own. (b) Is a tKD Euler micrograph of the same region, as indicated by the blue arrows. Preliminary results indicate $\mathrm{UC}_{2}$ as the bulk uranium precipitate. 